\title{
Economic Analysis of Heat Pump Recovery System for Circulating Water Waste Heat in Power Plant
}

\author{
Ze Wang ${ }^{1}$, Honghong Shen ${ }^{1}$, Qunyin $\mathrm{Gu}^{2}$, Daoyuan Wen ${ }^{2}$, Gang Liu ${ }^{1,3}$, Weijun $\mathrm{Gao}^{2}$, and Jianxing Ren ${ }^{1}$ \\ ${ }^{1}$ Colleg of Energy and Mechanical Engineering, Shanghai University of Electric Power, Shanghai, China \\ ${ }^{2}$ Department of International Environmental Engineering, 'The University of Kitakyushu, Fukuoka, Japan \\ ${ }^{3}$ Guodian Tongling Power Generation Co. Ltd, Anhui, China
}

\begin{abstract}
The use of heat pump technology to recover the waste heat of circulating water from the power plant instead of steam extraction for heating can not only improve the thermal efficiency of the unit and reduce the loss of cold source, but also has great advantages in energy saving. This paper uses absorption and compression heat pumps to recover the waste heat of circulating water in the power plant to study its energysaving benefits. Under the same heating load, the economics of the two heat pumps are calculated and analyzed. The results show that the energy-saving benefits of absorption heat pump units are far greater than compression units. But in terms of water saving, the water saving capacity of the compression heat pump unit is higher than that of the absorption heat pump.
\end{abstract}

\section{Introduction}

At present, my country's economy is developing rapidly, and the total energy consumption has also risen sharply during the development process. From 2011 to 2017, the total energy consumption has increased by 1.25 billion tons (calculated by standard coal), including construction and industrial sectors. It accounts for $90 \%$ of the total energy consumption, and it can be described as a big energy consumer ${ }^{[1]}$. Our country uses thermal power plants as the main power source and is the mainstay of the power system. However, regardless of the fuel used in thermal power plants, most of their heat is discharged into the environment through circulating cooling water and flue gas. The heat sources carried by these working fluids are low-grade heat sources, which cannot be used directly and can only be discharged into the atmosphere ${ }^{[3]}$, which causes serious energy waste, and the emission of lowgrade energy also causes water resources. Problems such as waste and air pollution ${ }^{[4]}$. This problem also exists widely in the United States and Europe and has attracted national attention. Therefore, the effective use of waste heat resources in power plants has important practical significance for energy conservation and emission reduction in my country and the world ${ }^{[5]}$.

Recovering waste heat and using it effectively is an effective way to solve the above-mentioned problems. Heat pumps are one of the effective ways to recover waste heat from power plants. Low-grade heat sources can be converted into high-grade heat sources to be used. Heat pumps can be used according to different drive types. It is a compression heat pump and an absorption heat pump. Compression heat pumps are used to convert electrical energy into heat energy to increase the temperature of lowgrade heat sources, and are mainly composed of a compressor, a condenser, an expansion valve and an evaporator ${ }^{[6]}$. The absorption heat pump uses steam as the driving heat source to increase the heat energy of the lowgrade heat source, which is mainly composed of four parts: a generator, an absorber, an evaporator and a condenser.

Compression and absorption heat pumps have many differences in real applications, the most notable is the difference in the driving energy of the two. The driving energy of the compression heat pump is electric energy, and the driving energy of the absorption heat pump is steam. Secondly, the energy efficiency coefficient of the absorption heat pump is lower than that of the compression heat pump. This is because the driving energy of the compression heat source is high-grade electric energy, and it occupies a small area. The setting is flexible ${ }^{[7]}$, but the absorption heat pump has fewer parts and less wear, so it is difficult to distinguish the pros and cons of the two ${ }^{[8]}$.

\section{Heat pump system}

\subsection{Compression heat pump recovery power plant circulating water waste heat system}

The driving energy of the compression heat pump is electric energy, and its working process is to allow the working fluid to continuously complete the thermal cycle of compression, condensation, throttling, and evaporation, thereby increasing the temperature of the user's water supply. The system flow chart is shown in Figure 1. The heat pump working fluid absorbs the heat of the 
circulating cooling water in the evaporator, raises the temperature and pressure through the compressor, then releases the heat to the heating hot water through the condenser, and finally passes through the throttle valve to reduce the temperature and pressure. Then return to the evaporator to continue to absorb heat.

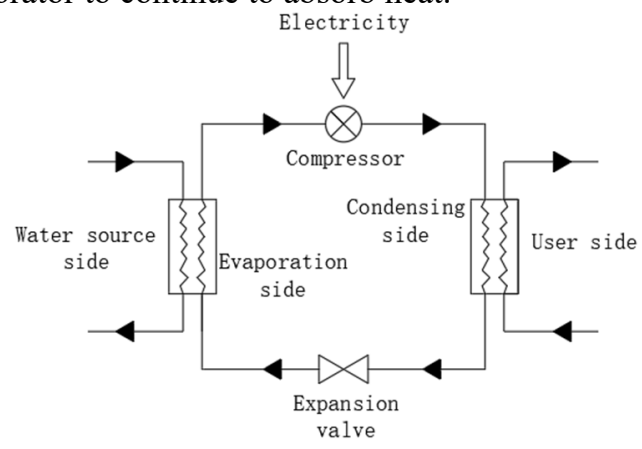

Figure 1 Flow chart of compression heat pump heating system

If other losses are ignored, for the compression heat pump heating cycle, the energy balance from the first law of thermodynamics can be used to obtain the following relationship:

$$
Q_{\mathrm{H}}=Q+W
$$

Among them, $\mathrm{Q}_{\mathrm{H}}$ represents the energy output by the condenser, that is, the heating capacity of the water source heat pump $(\mathrm{kW})$; Q represents the heat extracted by the evaporator from the heat source $(\mathrm{kW})$; W represents the electric power consumed by the compressor $(\mathrm{kW})$; in the heat pump system, The heating performance coefficient COP is used to measure the performance of the heat pump, which is defined as: $\mathrm{COP}=\mathrm{Q}_{\mathrm{H}} / \mathrm{W}$

The value of COP indicates the efficiency of the heat pump. The larger the value, the more heat is generated, and the better the energy saving effect of the water source heat pump. At present, the coefficient of performance of the compression heat pump is generally between 3 and 6 , that is, the heating capacity is 3 to 6 times the power consumption ${ }^{[9]}$.

\subsection{Absorption heat pump recovery power plant circulating water waste heat system}

Absorption heat pump uses steam turbine extraction steam as driving steam. Its working principle is that the generator absorbs the heat of high-temperature driving steam, part of the heat is transferred to the absorber, and the other part is transferred to the condenser; The evaporator absorbs the heat of the circulating cooling water and transmits it to the absorber; the absorber absorbs the heat from the generator and the evaporator and heats the hot water back to increase the temperature, and the condenser absorbs the heat from the generator to heat the hot water again, and the whole process The hot water is heated twice in the absorber and condenser in sequence. The flow chart of the heat pump system is shown in Figure 2

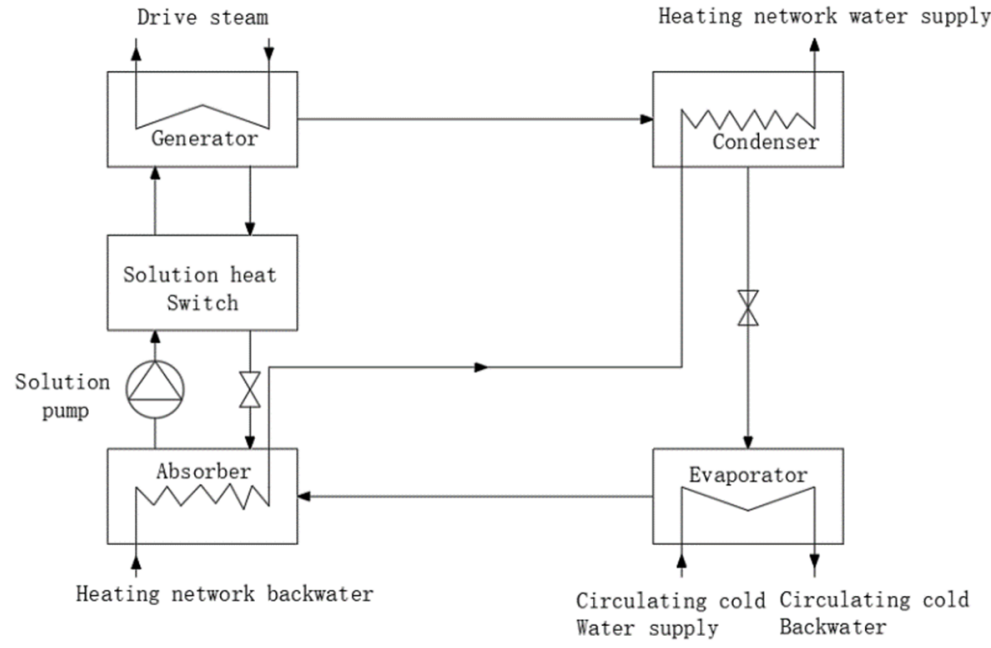

Figure 2 Flow chart of absorption heat pump heating system

Regardless of the heat loss caused by the work of the pump and the heat exchange between the system and the environment, the system heat balance is:

$$
Q_{a}+Q_{k}=Q_{g}+Q_{o}
$$

Among them, $\mathrm{Q}_{\mathrm{a}}$ represents the heat released by the absorber to the external environment, that is, the heat load of the absorber $(\mathrm{kW}) ; \mathrm{Q}_{\mathrm{k}}$ represents the heat released by the condenser to the external environment, and the heat load of the condenser $(\mathrm{kW})$; $\mathrm{Q}_{\mathrm{g}}$ represents the working fluid against the generator The heat absorbed from the high-temperature heat source in the heat pump is the heat $(\mathrm{kW})$ of the heat source driven by the heat pump; $\mathrm{Q}_{\mathrm{o}}$ is the heat absorbed from the low-temperature heat source in the evaporator, that is, the evaporator heat load $(\mathrm{kW})$; the coefficient of performance of the absorption heat pump is defined by the COP for:

$$
C O P=\frac{\text { Output the energy of hot water }}{\text { Drive the energy supplied by the heat source }}=\frac{Q_{a}+Q_{k}}{Q_{g}}
$$

At present, the coefficient of performance of the first type absorption heat pump is generally between 1.6 and $2.4^{[10]}$.
In the following, two actual cases of heat pump units replacing extraction steam to provide heat for users are used to analyze their economic performance. 


\section{Comparison of thermal economy of heat pump heating system}

Taking heating in a certain area as an example, the thermal calculation is performed on absorption and compression heat pumps for heating users. The $350 \mathrm{MW}$ condensing heat supply unit of the thermal power plant in this area uses $0.26 \mathrm{MW}, 206^{\circ} \mathrm{C}$ extraction steam to supply heat for users, and heats the heating network water from $55^{\circ} \mathrm{C}$ to $90^{\circ} \mathrm{C}$ for users. The design flow of primary network hot water is $2650 \mathrm{t} / \mathrm{h}$, and the heat load is It is $108 \mathrm{MW}$. The heating parameters of the unit are shown in Table 1.

Tab1. Some parameters of heating

\begin{tabular}{|c|c|}
\hline project & parameter \\
\hline Extraction steam pressure $(\mathrm{MW})$ & 0.3 \\
\hline Extraction steam temperature $\left({ }^{\circ} \mathrm{C}\right)$ & 206 \\
\hline Extraction steam enthalpy $(\mathrm{kJ} / \mathrm{kg})$ & 2947.61 \\
\hline Hydrophobic enthalpy $(\mathrm{kJ} / \mathrm{kg})$ & 472.4 \\
\hline Heating extraction steam flow $(\mathrm{t} / \mathrm{h})$ & 162 \\
\hline $\begin{array}{c}\text { Water supply temperature of heating } \\
\text { network }\left({ }^{\circ} \mathrm{C}\right)\end{array}$ & 90 \\
\hline $\begin{array}{c}\text { Water supply enthalpy of heating } \\
\text { network }(\mathrm{kJ} / \mathrm{kg})\end{array}$ & 376.97 \\
\hline $\begin{array}{c}\text { Return water temperature of heating } \\
\text { network }\left({ }^{\circ} \mathrm{C}\right)\end{array}$ & 230.24 \\
\hline $\begin{array}{c}\text { Heat network return water enthalpy } \\
(\mathrm{kJ} / \mathrm{kg})\end{array}$ & 97 \\
\hline $\begin{array}{c}\text { Generator efficiency }(\%) \\
\text { Steam turbine exhaust steam enthalpy } \\
(\mathrm{kJ} / \mathrm{kg})\end{array}$ & 2310.9 \\
\hline
\end{tabular}

\subsection{Thermal Economic Analysis of Compression Heat Pump Heating System}

Using a compression heat pump with a COP of 4.5 , and the circulating water temperature is reduced from $29^{\circ} \mathrm{C}$ to $20^{\circ} \mathrm{C}$. To meet the user's $108 \mathrm{MW}$ heating demand, power consumption $\mathrm{W}=24 \mathrm{MW}$ is required. After the heat pump is used for heating, the heating extraction steam continues to do work in the steam turbine, which can increase the work capacity by $28 \mathrm{MW}$. Regardless of the unit loss, the unit's power increase is $4 \mathrm{MW}$, saving $1379.2 \mathrm{~kg} / \mathrm{h}$ of standard coal, and can recover $84 \mathrm{MW}$ of circulating water waste heat from the power plant. The circulating water volume of the compression heat pump is $9037.65 \mathrm{t} / \mathrm{h}$.

\subsection{Thermal Economic Analysis of Absorption Heat Pump Heating System}

At present, the common absorption heat pump has a COP of 1.7. Under such a coefficient of performance, the heat pump has the best efficiency. Therefore, the heat pump with $\mathrm{COP}=1.7$ is used as the heating system, and the absorption heat pump uses the original heating extraction steam as the driving steam. The thermal conditions are basically the same as the extraction steam heating. The heating capacity of the power plant is $108 \mathrm{MW}$, so the heat required to drive the heat source is $63.5 \mathrm{MW}$, the calculated extraction steam is $92.36 \mathrm{t} / \mathrm{h}$, and the saved extraction steam is $69.63 \mathrm{t} / \mathrm{h}$. The saved extraction steam enters the steam turbine to do more work. The work volume is
16.4MW, the standard coal is saved $5654.72 \mathrm{~kg} / \mathrm{h}$, the circulating water waste heat of the power plant is $34.5 \mathrm{MW}$, and the circulating water flowing through the absorption heat pump is $3711.89 \mathrm{t} / \mathrm{h}$.

Tab2. Comparison of thermal economy of compression and absorption heat pump heating systems

\begin{tabular}{|c|c|c|}
\hline \multirow{2}{*}{ project } & \multicolumn{2}{|c|}{ Heating method } \\
\cline { 2 - 3 } & $\begin{array}{c}\text { Compression } \\
\text { heat pump }\end{array}$ & $\begin{array}{c}\text { Absorption } \\
\text { heat pump }\end{array}$ \\
\hline $\begin{array}{c}\text { Unit heat supply } \\
\text { (MW) }\end{array}$ & 108 & 108 \\
\hline $\begin{array}{c}\text { Heating extraction } \\
\text { steam volume (t/h) }\end{array}$ & 0 & 92.36 \\
\hline $\begin{array}{c}\text { Save extraction steam } \\
(\mathrm{t} / \mathrm{h})\end{array}$ & 162 & 69.63 \\
\hline $\begin{array}{c}\text { Workmanship } \\
\text { increment (MW) }\end{array}$ & 4 & 16.4 \\
\hline $\begin{array}{c}\text { Recycling water } \\
\text { volume (t/h) }\end{array}$ & 9037.65 & 3711.89 \\
\hline $\begin{array}{c}\text { Recovery of residual } \\
\text { heat of circulating } \\
\text { water }(\mathrm{kJ} / \mathrm{h})\end{array}$ & $3.02 \times 10^{8}$ & $1.24 \times 10^{8}$ \\
\hline $\begin{array}{c}\text { Save standard coal } \\
\text { (kg/h) }\end{array}$ & 5654.72 & 1379.2 \\
\hline
\end{tabular}

According to Table 2 it can be seen that compared with the traditional steam extraction heating, the energy-saving benefits of the two methods are far greater than the direct extraction steam heating unit. The energy-saving effect of the absorption heat pump is greater than that of the compression heat pump in improving the efficiency of the power plant itself, and the energy-saving effect of the compression heat pump is greater than that of the absorption heat pump in terms of the recovery of circulating water waste heat. In general, the heat economy of heat supply units using absorption heat pumps is better. The annual heating season is 4 months, the total heating time is $2880 \mathrm{~h}$, the energy-saving income of the absorption heat pump is 26.84 million yuan, and the energy-saving income of the compression heat pump is At 6.54 million yuan, the annual total energy-saving income of absorption heat pump units is much higher than that of compression heat pump units.

\section{In conclusion}

1) According to case calculations, the two types of heat supply units have good energy-saving benefits in recycling waste heat from circulating water, and they are worthy of vigorous promotion. Compression heat pumps are greater than absorption heat pumps in terms of waste heat utilization, and are stronger than absorption heat pumps in their ability to promote low-grade heat sources, while absorption heat pumps are lower in energy consumption than compression heat pumps.

2 ) In the case of a certain heating load, the calculation and analysis of the two heat pump heating methods show that the economics of the absorption heat pump heating unit is better than the compression heat pump unit. During the entire heating period, the total energy-saving income obtained by the absorption heat pump unit is 20.3 million 
yuan higher than that of the compression heat pump unit. However, in terms of water saving, the water saving of the compression heat pump heating unit is much greater than that of the absorption heat pump heating unit, which is suitable for some water-scarce areas such as the Northwest.

\section{References}

1. Research Center for Building Energy Conservation, Tsinghua University. China Building Energy Conservation Annual Development Research Report 2019[M]. Beijing: China Building Industry Press, 2019: 86-67

2. HUSSAM J H, NAVID K, SULAIMAN A.et al. Waste heat recovery technologies and applications [J]. Thermal Science and Engineering Progress, 2018, 6: 268-289

3. Wang Xiaofei, Feng Lijun. Ultra-low emissions of biomass boiler flue gas-research on denitrification (cooperative whitening) technology[J]. Guangxi Energy Conservation, 2019(01):34-35.

4. Li Yan, Fu Lin, Zhang Shigang, Di Hongfa, Xiao Changlei. Overview of waste heat utilization technology of circulating water in power plant $[\mathrm{J}]$. Building Science,2010,26(10):10-14.

5. Michael Papapetrou; George Kosmadakis; Andrea Cipollina; Umberto La Commare; Giorgio Micale Industrial waste heat: Estimation of the technically available resource in the EU per industrial sector, temperature level and country [j] Applied Thermal Engineering,2018

6. Liu Zhongqiu, Zhang Guozhu, Qiu Yinchen, Zhang Juntai, Wang Shan, Liu Ming. Analysis of the potential and energy consumption characteristics of the integrated heat pump of the cogeneration unit to realize the thermoelectrocouple[J].Power Generation Technology, 2019, 40(03):253 -257.

7. Guo Xiaodan, Hu Sangao, Yang Kun, Xu Hong. Research on the utilization of waste heat from circulating water in heat pump recovery power plants[J]. Modern Electric Power,2010,27(02):58-61.

8. Zhang Junbo, Jin $\mathrm{Xu}$, Liu Zhongyan, Che Deyong, Sui Jun. Summary of advanced technology of absorption heat pump waste heat recovery[J]. Power Generation Technology,2020,41(03):269-280.

9. Guo Jianglong, Chang Shuping, Feng Aihua, Li Hao, Li Qiong. Economic analysis of the condensing heat of circulating water in power plants with compression and absorption heat pump recovery[J]. Steam Turbine Technology, 2012,54(05):379-380+ 388 .

10. Du Wenzhi, Guo Xiaohu, Zhu Xiaolong, Gou Yuanbo, $\mathrm{Wu}$ Di. Introduction to absorption heat pump technology and its research and development[J]. Shandong Chemical Industry, 2020, 49(16): 132+134. 